\title{
Do sexual health services encourage teenagers to use condoms? A longitudinal study
}

\author{
Alison Parkes, Marion Henderson, Daniel Wight
}

\begin{abstract}
Objective Sexual health services have the potential to encourage teenagers' condom use through both the free supply of condoms and counselling. This study investigated whether 15/16-year-olds who attended sexual health services used condoms more and had different beliefs about condoms compared to those who did not use these services.
\end{abstract}

Methods First, a cross-sectional multivariate model investigated the association between service visits and condom consistency (a ratio of the number of times a condom was used to the number of times a teenager had sexual intercourse in the past year) in teenagers at age $15 / 16$ years $(n=1013)$. Second, a longitudinal multivariate model examined links between service use and changes in condom-related cognitions measured at age $13 / 14$ and age $15 / 16$ years $(n=3432)$.

Results Visiting a service for free condoms was linked with greater condom consistency, after controlling for attitudes towards condoms, condom purchase and other factors. Visiting a service for other purposes was associated with lower consistency. Obtaining free condoms from services predicted greater condom selfefficacy and personal responsibility, and lower negative feelings relating to sexual pleasure when condoms were used. However, visiting a service for other purposes predicted less positive attitudes towards dual protection.

Conclusions Obtaining free condoms from services was associated with greater condom use and positive changes in attitudes towards condoms, although the role of service counselling remains unclear. Services could do more to stress the need for continued dual protection against sexually transmitted infections (STIs) when prescribing the pill.

J Fam Plann Reprod Health Care 2005; 31(4): 271-280

(Accepted 29 April 2005)

\section{Key message points}

- Obtaining free condoms from services seems to improve attitudes towards condoms and encourage their use.

- Teenagers using services for other purposes (such as the pill) were less likely to use condoms.

- Services could do more to stress the need for continued dual protection against STIs and pregnancy when prescribing the pill.
MRC Social and Public Health Sciences Unit, University of Glasgow, Glasgow, UK

Alison Parkes, MA, PhD, Researcher

Marion Henderson, BA, Senior Researcher

Daniel Wight, BA, PhD, Senior Researcher

Correspondence to: Dr Alison Parkes, MRC Social and Public Health Sciences Unit, University of Glasgow, 4 Lilybank Gardens, University of Glasgow, Glasgow G12 8RZ, UK. E-mail: alison-p@msoc.mrc.gla.ac.uk

\section{Introduction}

Condoms are the most commonly used contraceptive amongst UK teenagers.1,2 Condoms have several advantages from a teenage perspective: they are widely available and can be used without much prior planning and without the need for medical consultation. They also provide effective protection against sexually transmitted infections (STIs). Nevertheless, there is evidence that many teenagers are inconsistent users of condoms, with frequency of intercourse and number of partners inversely related to condom consistency, $, 4,4$ and dual protection (using a condom with the pill) remaining low, especially amongst high-risk groups. ${ }^{5}$

It is likely that a number of different factors combine to influence teenagers' use of and intentions to use condoms, signalling the need to adopt a multifaceted approach to condom intervention programmes. Researchers have identified knowledge of health benefits/risks, attitudes towards condoms in relation to embarrassment and sexual pleasure, components of condom self-efficacy (such as acquisition, correct usage and negotiation with partner) and social norms of condom use as factors predicting teenagers' intention to use condoms ${ }^{4,6-15}$ Both gender $4,7,11$ and sexual experience ${ }^{7,16}$ may moderate teenagers' attitudes towards condoms and condom intentions. Situational factors also need to be taken into account. The nature and duration of a relationship may be important, ${ }^{17}$ condoms often being substituted with the pill in non-casual relationships once trust is established. ${ }^{18,19}$ Differences between partners, such as in age, may also result in less consistent use. ${ }^{20,21}$

Clearly, one of the prerequisites for consistent condom use is access to a supply of condoms. However, as condoms are available commercially, the importance of sexual health services' supply of free condoms is unclear. Services also supply other contraceptives, primarily the pill, that teenagers may substitute for condoms if they do not value the need for dual protection. As well as supplying condoms, service staff may promote their use through counselling: providing information, instruction and advice about condoms in relation to protection against unwanted pregnancy and STIs. What is the evidence that supply of free condoms or counselling about condom use encourages teenagers' use of condoms?

UK evidence on the effectiveness of clinics is restricted to their effect on pregnancy rates and outcomes. Some studies have shown that greater clinic availability reduces pregnancy rates, 22,23 while others found no effect. 24,25

In the USA there is comparatively little evidence for the effectiveness of clinic-based interventions on condom use by adolescents, as opposed to all age groups or groups at risk from HIV/AIDS. ${ }^{26-28}$ Existing studies focus on condom consistency, although services also have a role in ensuring the correct use of condoms. Errors in condom use among teenagers may be relatively common, ${ }^{29-31}$ and Crosby et al. ${ }^{32}$ warn that self-efficacy is not necessarily related to demonstrated skill.

Studies in the USA have most commonly been of school-based condom provision, with mixed results. ${ }^{33-37}$ Most condom availability programmes are accompanied by counselling. ${ }^{38}$ Studies of adolescent counselling programmes often compare clinic users and non-users 


\section{ARTICLE}

without controlling for selection effects, while studies comparing different types of clinic usually offer inadequate controls. ${ }^{39}$ DiCenso et al.'s review ${ }^{40}$ of randomised trials to reduce unintended adolescent pregnancies found only one clinic intervention that met their inclusion criteria: this had no significant effect. More recently, Robin et al.'s review ${ }^{41}$ of behavioural interventions among adolescents found only two clinic-based studies; one with positive effects of behavioural skills training on condom use and the other with no intervention effect.

\section{Study overview}

As part of a randomised trial of the SHARE sex education programme, ${ }^{42}$ longitudinal data were collected on teenagers' sexual behaviour, attitudes towards and use of condoms, and their use of sexual health services. In a previous paper the SHARE dataset was used to explore factors associated with teenagers' use of sexual health services. ${ }^{43}$ At a time of rising numbers of STI diagnoses ${ }^{44}$ and increased risky sexual behaviour, ${ }^{45}$ these data also offer a useful opportunity to explore links between service visits and condom use. Unfortunately we do not know the extent to which service users received any counselling. Further work will be required to clarify the relative influences of free condom supply and counselling practice.

Two main hypotheses were explored. First, that sexual health services promote greater condom consistency, as measured by the ratio of condom use to the number of times a teenager has sexual intercourse. The aim of this part of the investigation was to provide evidence that access to a free supply of condoms encourages teenagers to use them more frequently than they would otherwise do. Our model included controls for teenagers' purchase of condoms and individual attitudes/intentions towards using condoms (collectively termed 'condom cognitions').

The second hypothesis was that visiting a service to get free condoms will modify condom cognitions. Here the aim was to explore whether in the context of other possible influences on teenagers (such as friends, school sex education and any experience of sexual intercourse) there was evidence that service use was associated with changed attitudes towards condoms. The study is exploratory in nature, as we examined changes in condom cognitions over a 2-year period in relation to any use of sexual health services during this time for free condoms and/or other purposes, without having information on the number, timing and content of service visits. In particular, we do not know the extent to which teenagers received information and advice about condoms from services, so we cannot attribute an improved attitude towards condoms to the effects of service counselling. However, in the absence of UK (or many USA) studies on the impact of sexual health services, the analysis is useful as a first step towards establishing how services may, in the context of other competing influences, have most impact on teenagers' attitudes and intentions towards condom use.

\section{Design and methods}

Following approval by Glasgow University's Ethical Committee for Non-Clinical Research Involving Human Subjects, all 47 non-denominational state secondary schools within $24 \mathrm{~km}$ of the main cities in Lothian and Tayside, Scotland were invited to participate in the SHARE controlled trial of school sex education, ${ }^{42}$ with the exception of five pilot schools. Twenty-five schools elected to take part. Parents were given the opportunity to withdraw their children, and pupils were also given the option to withdraw or omit questions at any stage. Taking into account these opt-outs and absences from school, the participation rate at baseline in 1996/1997 was 94\%. At the age 15/16 years follow-up in 1998/99 the response rate was $69 \%$ of the total eligible sample. The fall was mainly attributable to lower participation among school leavers completing postal questionnaires. Only $2 \%$ of those still at school chose to opt out.

Questionnaires were administered by researchers under examination conditions, with school leavers at age 15/16 years completing a postal questionnaire at home. At baseline (age 13/14 years; $n=7616$ ) and follow-up (age $15 / 16$ years; $n=5854$ ) pupils provided information about their attitudes towards condoms and their sexual behaviour. At age 15/16 years they also reported on use of sexual health services, purchase of condoms and opinions of their school sex education: all these events took place between ages 13/14 and 15/16 years. Most of the analysis was based on a maximum sample of 5486 teenagers who provided information at age 15/16 years about obtaining condoms free from sexual health services during the previous 2 years. Part of the analysis was based on a lower maximum sample of 617 teenagers who provided information on the type of service used for condoms.

The analysis used weighted data to compensate for attrition in the follow-up sample being greater for boys, lower social class and those reporting sex at baseline, maintaining the representativeness of the sample compared to the 1991 census that was established at baseline. ${ }^{17}$

\section{Measures}

Following Abraham et al.'s use of the SHARE dataset, 46 condom consistency was computed, for those who had had sexual intercourse more than once during the year preceding the follow-up survey, by dividing a condom use score by a frequency of intercourse score, so that consistency ranged from 0 to 1 . [NB. Condom use was given by responses to the question 'How many times did you use a condom in the last year?' and intercourse frequency by responses to the question 'How many times did you have sex in the last year?'. Responses in both cases were scored $0,1,2,3,4-6,7-9$, more than 10.] This measure was strongly correlated with answers to 'How often did you use a condom, ever?' [scored from never (1) to always (5); $r=0.82, p<0.0001]$, indicating good reliability in the reporting of condom consistency.

Condom acquisition at age 15/16 years over the previous year was measured using the two questions: 'In the last 2 years, have you gone to any health services to get condoms?' (referred to as free condoms) and 'In the last year, have you bought condoms?' (referred to as bought condoms). Although the first measure refers to a longer period than that for which condom consistency was measured, a separate question showed that $91 \%$ of those getting condoms from services in the last 2 years also got condoms free in the last year only. Over a quarter $(28 \%)$ of the age $15 / 16$ years sample $(n=5747)$ had obtained free condoms in the past 2 years, while $26 \%$ had bought condoms in the past year; $10 \%$ had done both.

In addition, a measure was derived for use of sexual health services in the last 2 years for other purposes (referred to as other purpose). Nearly one-fifth (18\%) of the age 15/16 years sample had used services for other purposes in the last 2 years, with most $(77 \%)$ visits made for contraception. Some $45 \%$ of those visiting services for free condoms also visited for other purposes, with more girls $(61 \%)$ than boys $(23 \%)$ doing so. We have no information on the main purpose, number and timing of visits. 
Only $43 \%$ of teenagers who reported accessing free condoms identified the type of service used ${ }^{43}$ Responses were divided into youth or mainstream services: most youth services were designated times for young people within family planning clinics, with four other services designed exclusively for young people. Mainstream services included general practitioner services, family planning clinics without specific times for young people as well as other services such as hospital clinics. Over half $(56 \%)$ of those supplying information about the type of service used for condoms $(n=617)$ visited a youth service.

Abraham et al.'s model of condom consistency, ${ }^{46}$ based on the Theory of Planned Behaviour, ${ }^{47-50}$ used 12 potential cognitive correlates of condom use measured at age 15/16 years: these covered intentions to use condoms, preparatory intentions, attitudes towards condom use, perceived condom efficacy, normative beliefs, condom use self-efficacy (perceived behavioural control), anticipated regret and knowledge of sexual health. Questions designed to measure these components of the Theory of Planned Behaviour were based on existing research literature and piloted using 337 age 13and 14-year-old pupils in five Scottish schools using a mixture of quantitative and qualitative techniques. Abraham and colleagues subsequently 46 found that an extended model of planned behaviour using intention, condom use self-efficacy, attitudes, descriptive norm and anticipated regret explained $25.9 \%$ of the variance in condom consistency reported at age $15 / 16$ years in the SHARE dataset.

This paper built on Abraham et al.'s model, increasing its scope to consider additional condom cognitions (intention to use both the condom and pill, personal responsibility for using condoms, two additional condom self-efficacy measures and a health belief, perceived STI risk) as well as cognitions related to use of the pill (intentions to use the pill, pill efficacy, and three measures of pill self-efficacy), since the pill may be seen as an alternative form of contraception to condoms. As more general controls for attitudes towards the risk of pregnancy we included gender and a measure of fear of unwanted pregnancy. We also considered some contextual influences to compare with the service visits modelled: these comprised talking with friends about contraception; ratings of school sex education coverage and effectiveness; as well as the extent of teenagers' sexual experience (the number of times teenagers reported having sexual intercourse in the past year and whether they had intercourse with more than one partner).

Table 1 sets out the cognition variables giving the italicised names used in this paper; together with information on when the variable was measured, questionnaire wording, response and scaling. Three cognitions, personal responsibility, easy negotiate and less fun, were each mean scores of two items that had highly correlated responses at both age 13/14 and age 15/16 years (Cronbach's alpha>0.7). Although attitudes towards condoms were combined in the Abraham et al. model, giving a mean score for three items at age 15/16 years, reliability for such a measure was not satisfactory at age 13/14 years. Two separate measures (embarrassment and less fun) were used here instead, because of the need to be able to make direct comparisons between baseline and follow-up cognition measures in Part 2 of the analysis. The descriptive norm, friends use condoms, scaled from 1 to 5 in Abraham et al.'s model, has been simplified to a binary variable (agree or unsure/disagree) in this paper.

\section{Part 1: Service use and condom consistency:} cross-sectional models using data reported at $15 / 16$ years

Methods

We first examined the bivariate relationship of free condoms with consistent use of condoms during the year before follow-up at age 15/16 years. We also examined whether teenagers who used youth services differed with respect to condom consistency from those who had used only mainstream services. As potential additional predictors of condom consistency, the age 15/16 years variables listed in Table 1 were examined for their bivariate relationship with this outcome. Only those variables that showed a significant relationship with condom consistency at the $p<0.05$ level were considered as potential candidates for inclusion in the multivariate models.

Multivariate models of condom consistency were then constructed using SPSS v.11.5 (SPSS Inc., Chicago, IL, USA) mixed models procedure to control for clustering of responses by school. The sample consisted of teenagers reporting intercourse more than once by age $15 / 16$ years for whom there was complete information for all other independent variables with a significant $(p<0.05)$ bivariate relationship with consistency $(n=1013)$. All models controlled for gender, sex with one/more partners, number of times teenager had sex in the past year, fear pregnancy and school sex education effectiveness. Further selection of cognition variables for inclusion in the final set of models was performed, guided by the Theory of Planned Behaviour which suggests that condom intentions will show the most direct relationship with condom use. The three stages were condom intentions, other condom cognitions and pill cognitions. At each selection stage, cognitions significant at the $p<0.05$ level were included in the following stage. The final set of three models comprised, in addition to the controls mentioned: Model 1, cognitions; Model 2, bought condoms, free condoms and other purpose; and Model 3, full set of variables.

\section{Results}

In this part of this cross-sectional analysis there was evidence that teenagers who obtained free condoms from services were more likely to use condoms than other teenagers, even controlling for factors such as individual condom- and pill-related cognitions, amount of sexual experience, buying condoms and other types of service visit. However, visiting a service for other purposes was associated with less consistent condom use.

Condom consistency in the year preceding follow-up was slightly higher for those who obtained condoms free from services compared to those who had not (service users 0.82 , non-users $0.78 ; n=1302, p<0.01$ ). Consistency was also higher for those who had visited youth services for condoms compared to those visiting mainstream services, although the difference here was not significant (youth services 0.85 , mainstream $0.80 ; n=414, p<0.09$ ).

No significant bivariate relationship with condom consistency was found for pill use intentions, pill efficacy, sex education coverage, talking with friends or knowledge: these variables were therefore not included in the multivariate models of condom consistency.

In Model 1, one relationship variable, gender and 12 cognitions were found to be significant predictors of condom consistency (Table 2, first set of figures). Girls and those who reported intercourse with more than one partner were less consistent condom users. Condom cognitions linked with increased condom consistency included greater intend always, intend persuade, personal responsibility, easy negotiate and regret pill only, together with reduced 


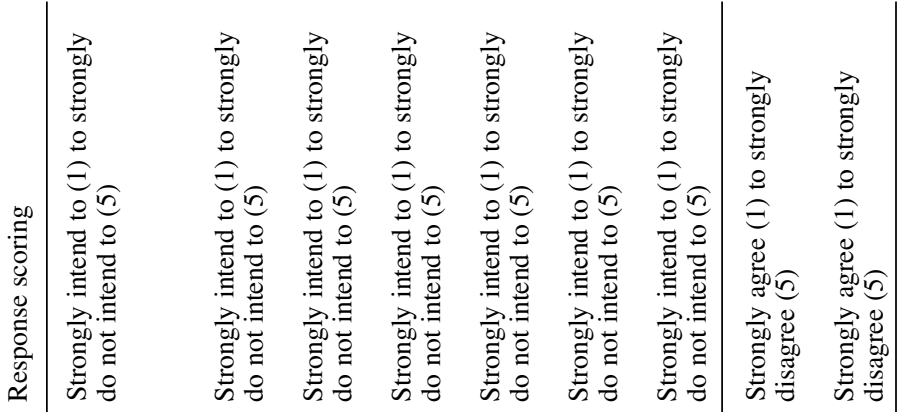

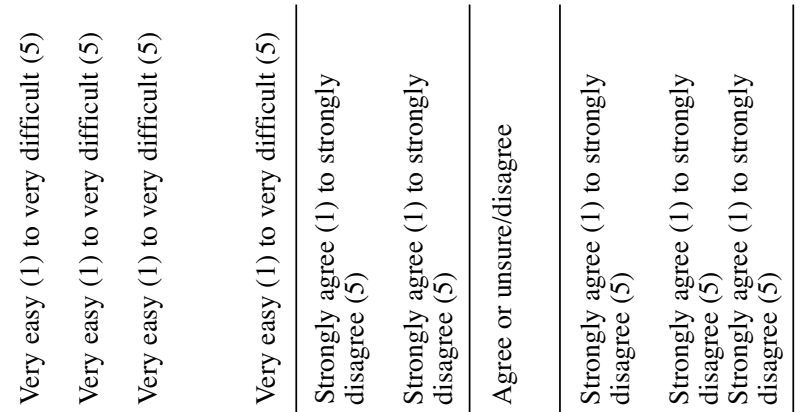

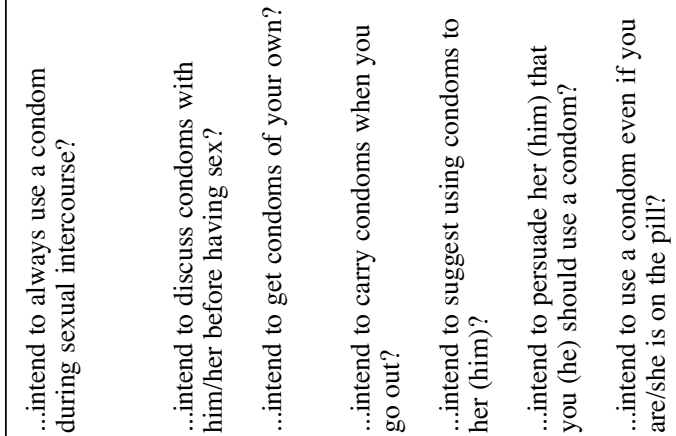

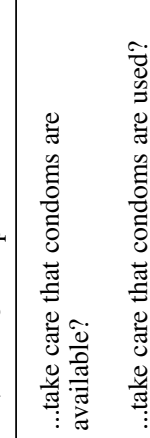

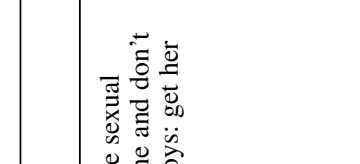

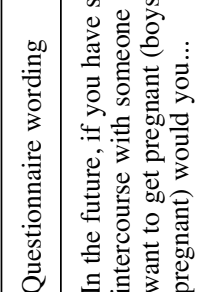
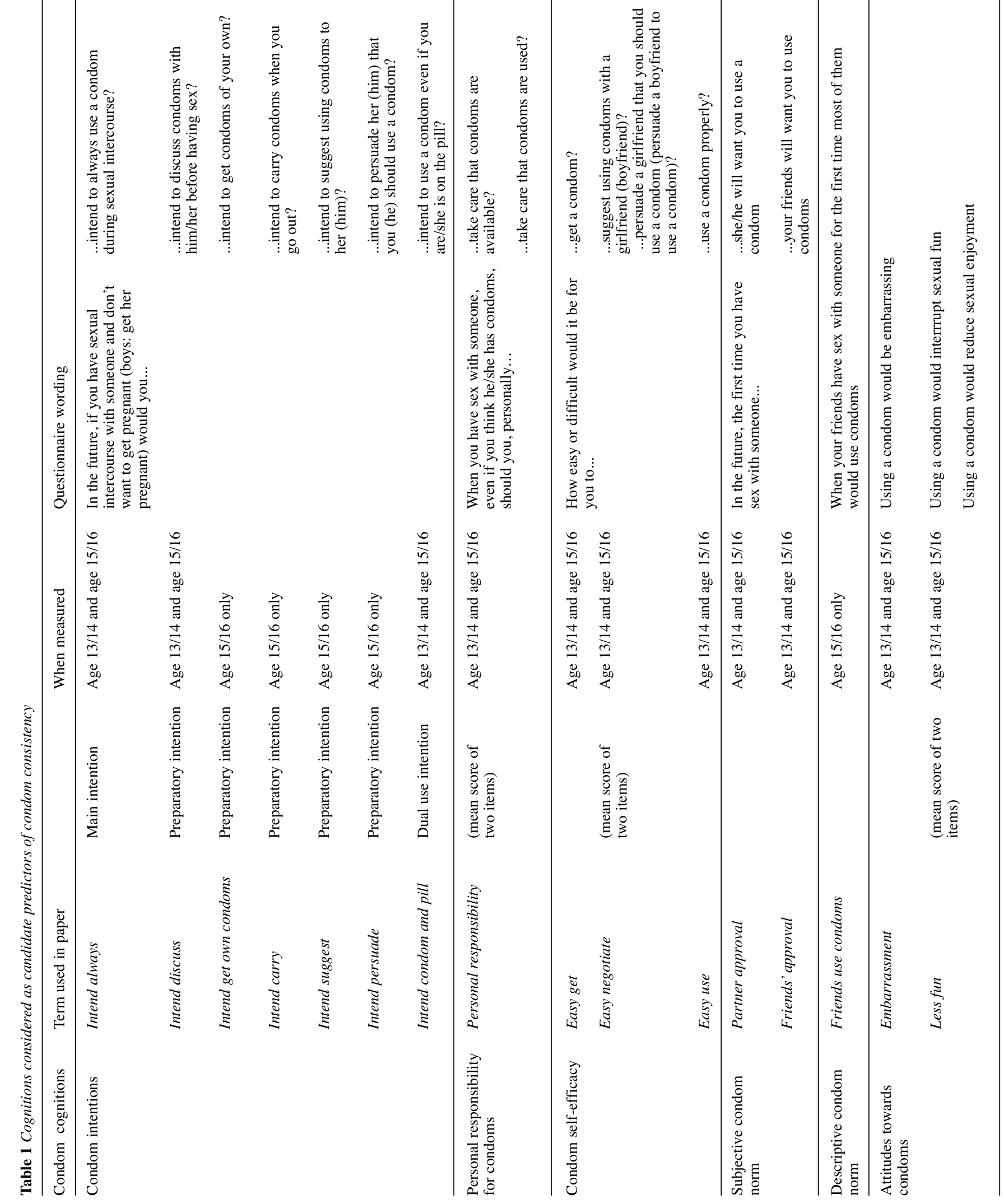


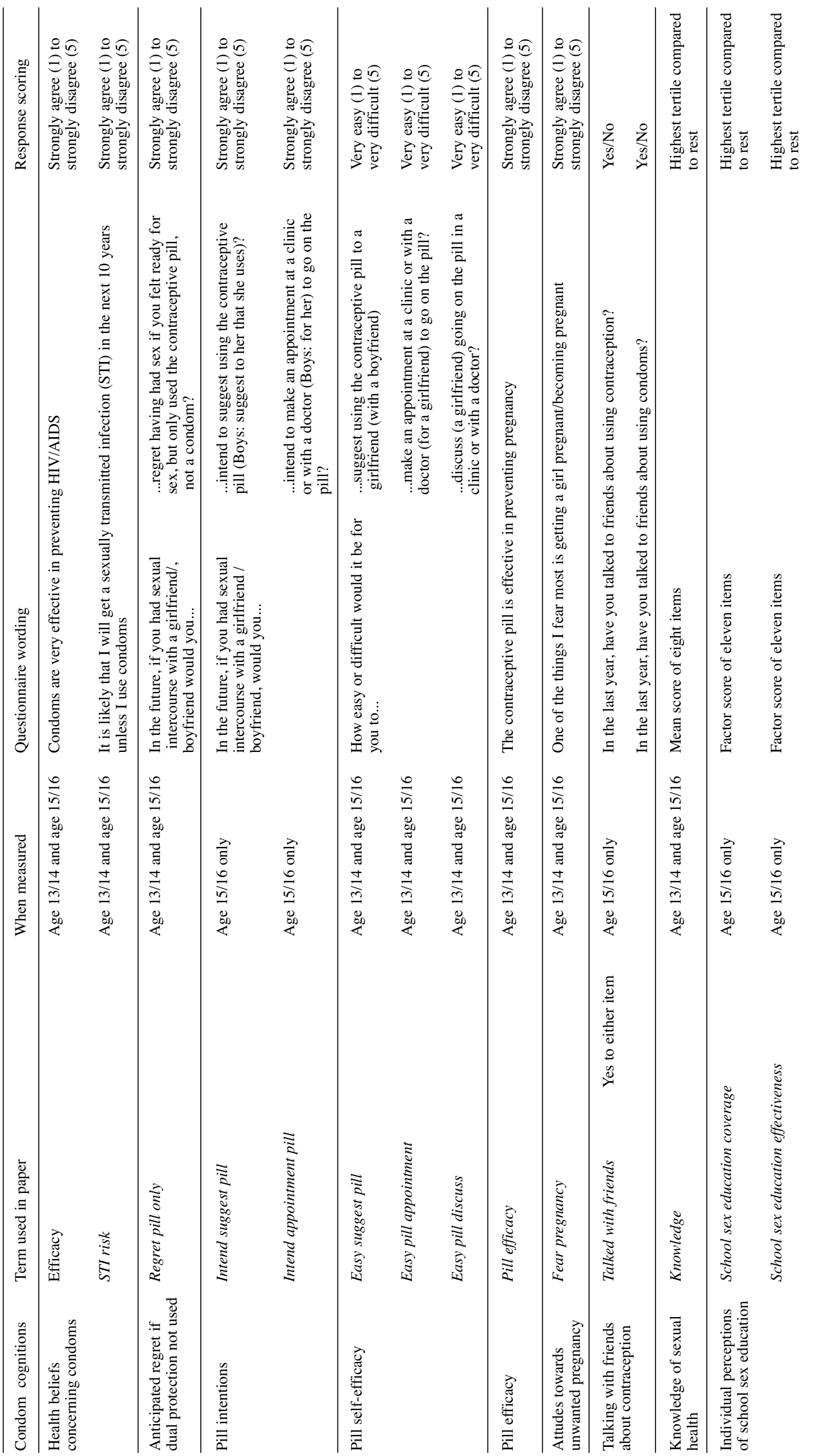

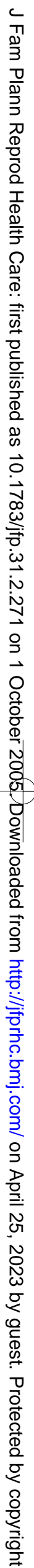




\section{ARTICLE}

Table 2 Predictors of condom consistency for those reporting sexual intercourse more than once at age 15/16 years $(\mathrm{n}=1013)$

\begin{tabular}{|c|c|c|c|c|c|c|c|c|c|c|c|c|}
\hline \multirow{3}{*}{$\begin{array}{l}-2 \text { Log likelihood } \\
\text { Parameter }\end{array}$} & \multicolumn{4}{|l|}{$\begin{array}{l}\text { Model } 1 \\
88.50\end{array}$} & \multicolumn{4}{|l|}{$\begin{array}{l}\text { Model } 2 \\
250.20\end{array}$} & \multicolumn{4}{|l|}{$\begin{array}{l}\text { Model } 3 \\
40.90\end{array}$} \\
\hline & \multirow[t]{2}{*}{ Coefficient } & \multicolumn{2}{|l|}{$95 \% \mathrm{CI}$} & \multirow[t]{2}{*}{$p$} & \multirow[t]{2}{*}{ Coefficient } & \multicolumn{2}{|l|}{$95 \% \mathrm{CI}$} & \multirow[t]{2}{*}{$p$} & \multirow[t]{2}{*}{ Coefficient } & \multicolumn{2}{|l|}{$95 \% \mathrm{CI}$} & \multirow[t]{2}{*}{$p$} \\
\hline & & Lower & Upper & & & Lower & Upper & & & Lower & Upper & \\
\hline Gender (boys) & 0.05 & 0.02 & 0.08 & $* *$ & -0.03 & -0.06 & 0.01 & NS & 0.00 & -0.04 & 0.03 & NS \\
\hline Number of times had sex in year & 0.01 & 0.00 & 0.02 & NS & 0.00 & -0.02 & 0.01 & NS & 0.01 & 0.00 & 0.02 & NS \\
\hline $\begin{array}{l}\text { Intercourse with more than one } \\
\text { partner }\end{array}$ & -0.07 & -0.10 & -0.04 & $* * *$ & -0.01 & -0.13 & -0.06 & *** & -0.08 & -0.11 & -0.04 & $* * *$ \\
\hline $\begin{array}{l}\text { School sex education } \\
\text { effectiveness (high rating) }\end{array}$ & 0.01 & 0.00 & 0.02 & $*$ & 0.02 & 0.01 & 0.03 & $* *$ & 0.01 & 0.00 & 0.02 & NS \\
\hline Fear pregnancy & 0.01 & 0.00 & 0.03 & $*$ & 0.03 & 0.02 & 0.04 & $* * *$ & 0.01 & 0.00 & 0.03 & $*$ \\
\hline Intend always & 0.05 & 0.03 & 0.07 & $* * *$ & & & & & 0.04 & 0.02 & 0.06 & $* * *$ \\
\hline Intend persuade & 0.03 & 0.00 & 0.05 & $*$ & & & & & 0.02 & 0.00 & 0.05 & $*$ \\
\hline Intend discuss & -0.04 & -0.06 & -0.02 & $* * *$ & & & & & -0.03 & -0.05 & -0.01 & $* * *$ \\
\hline Personal responsibility & 0.04 & 0.01 & 0.06 & $*$ & & & & & 0.03 & 0.00 & 0.06 & $*$ \\
\hline Easy negotiate & 0.06 & 0.03 & 0.08 & $* * *$ & & & & & 0.05 & 0.03 & 0.08 & $* * *$ \\
\hline Friends use condoms (agree) & 0.07 & 0.04 & 0.10 & $* * *$ & & & & & 0.06 & 0.03 & 0.10 & $* * *$ \\
\hline Embarrassment & -0.05 & -0.08 & -0.03 & $* * *$ & & & & & -0.05 & -0.07 & -0.02 & $* * *$ \\
\hline Less fun & -0.04 & -0.06 & -0.02 & $* * *$ & & & & & -0.04 & -0.05 & -0.02 & $* * *$ \\
\hline Regret pill only & 0.02 & 0.01 & 0.04 & $* *$ & & & & & 0.02 & 0.01 & 0.04 & $* * *$ \\
\hline Easy suggest pill & -0.05 & -0.07 & -0.03 & $* * *$ & & & & & -0.05 & -0.07 & -0.03 & $* * *$ \\
\hline Bought condoms & & & & & 0.16 & 0.13 & 0.20 & $* * *$ & 0.10 & 0.07 & 0.13 & $* * *$ \\
\hline Free condoms & & & & & 0.09 & 0.06 & 0.13 & $* * *$ & 0.06 & 0.03 & 0.09 & $* * *$ \\
\hline Other purpose & & & & & -0.11 & -0.15 & -0.07 & $* * *$ & -0.07 & -0.11 & -0.04 & $* * *$ \\
\hline
\end{tabular}

Cognitions all measured at age $15 / 16$ years. ${ }^{*} p<0.05,{ }^{*} p<0.01,{ }^{*} * *<0.001$ (two-tailed significance). NS, not significant

embarrassment and less fun (similar to Abraham et al.'s model ${ }^{46}$ ). A high rating of sex education effectiveness was also linked with greater condom consistency. However, easy suggest pill was linked with lower consistency; as was greater intend discuss - the latter may reflect a more ambivalent individual attitude towards condoms than the other two condom intentions.

Model 2 excluded condom and pill cognitions, but added free condoms, bought condoms and other purpose (Table 2, second set of figures). Free condoms and bought condoms were both associated with greater condom consistency, but other purpose was associated with reduced consistency (all $p<0.001$ ). Model 3 (Table 2, third set of figures) included all variables used in Models 1 and 2 and provided the best fit to the data. Free condoms and bought condoms were still both associated with greater condom consistency, and other purpose was associated with lower consistency (all $p<0.001)$. [NB. Interaction between free condoms and other purpose was explored but was found to be not significant.]. The coefficient for free condoms, although lower than for bought condoms, is comparable to that for agreeing that friends use condoms and exceeds that for high rating of school sex education effectiveness.

With the inclusion of free condoms, bought condoms and other purpose many of the coefficients for condom cognitions in Model 3 were slightly reduced compared to their values in Model 1. This was more pronounced for school sex education effectiveness, which lost significance: possibly because high rating of school sex education predicts service use. ${ }^{43}$ Similarly, the coefficients for bought condoms, free condoms and other purpose were reduced compared to their values in Model 2.

\section{Part 2: Service use and condom cognitions: longitudinal models for all teenagers regardless of sexual experience \\ Methods}

Fourteen condom cognitions were measured both at age $13 / 14$ and at age 15/16 years (see Table 1). Almost all these cognitions were potential candidates for Abraham et al.'s model of condom use, based on the Theory of Planned
Behaviour, ${ }^{46}$ comprising intentions, condom self-efficacy, subjective condom norms, health beliefs concerning condoms and anticipated regret (we have added personal responsibility for using condoms). All showed bivariate correlations with condom consistency (all $p<0.001$, except efficacy $p<0.01$ ), ranging from 0.42 and 0.37 in the case of intend always and personal responsibility, respectively, to 0.10 and 0.07 in the case of STD risk and efficacy. The relationship between free condoms and these cognitions at age 15/16 years, controlling for the level of each cognition at age 13/14 years, was investigated separately for each cognition using SPSS v.11.5 mixed models procedure to control for clustering of responses by school.

An extended model added gender and seven variables measured at age 15/16 years: first experience of sexual intercourse in the follow-up period, other purpose, bought condoms, friends use condoms, talking with friends (about contraception), and school sex education coverage and effectiveness. [NB. Each variable was found to have separate significant $(p<0.05)$ associations with age $15 / 16$ years cognitions (controlling for age 13/14 years cognitions) in exploratory bivariate analysis.] The sample for the extended model selected those who did not report sexual intercourse by baseline at age 13/14 years, and included only cases with complete information $(n=3432)$.

Similar methods were used to explore the relationship between service type (youth/mainstream) and cognition change.

\section{Results}

In this longitudinal analysis there was evidence that the likely impact of services on cognition change was small compared to the effects found for buying condoms or for other influences modelled, especially peer effects. In multivariate models, using services to get free condoms was associated with positive changes in perceived condom selfefficacy, personal responsibility for using condoms and attitudes towards condoms in relation to sexual pleasure. However, if teenagers used services for other purposes they developed more negative attitudes towards dual protection compared to those who did not use services in this way. 
ARTICLE

Table 3 Condom cognitions at age 15/16 years in relation to use of services to obtain free condoms

\begin{tabular}{|c|c|c|c|c|c|c|}
\hline \multirow{3}{*}{ Condom cognition } & \multirow{3}{*}{ Measure } & \multirow{3}{*}{ Total n } & \multicolumn{4}{|c|}{ Service used for free condoms } \\
\hline & & & \multirow[t]{2}{*}{ Coefficient } & \multicolumn{2}{|c|}{$95 \% \mathrm{CI}$} & \multirow[t]{2}{*}{$p$} \\
\hline & & & & Lower & Upper & \\
\hline \multirow[t]{3}{*}{ Condom intentions } & Intend always & 4795 & -0.05 & -0.10 & 0.01 & NS \\
\hline & Intend discuss & 4804 & 0.07 & 0.02 & 0.12 & $* *$ \\
\hline & Intend condom and pill & 4817 & -0.06 & -0.11 & -0.01 & * \\
\hline Personal responsibility to use condoms & Personal responsibility & 4767 & 0.07 & 0.03 & 0.11 & $* * *$ \\
\hline \multirow{3}{*}{ Condom self-efficacy } & Easy get & 4922 & 0.35 & 0.31 & 0.39 & $* * *$ \\
\hline & Easy negotiate & 4911 & 0.28 & 0.24 & 0.33 & $* * *$ \\
\hline & Easy use & 4891 & 0.29 & 0.25 & 0.34 & $* * *$ \\
\hline \multirow[t]{2}{*}{ Subjective condom norms } & Partner approval & 4611 & -0.01 & -0.07 & 0.04 & NS \\
\hline & Friends' approval & 4554 & 0.13 & 0.07 & 0.19 & $* * *$ \\
\hline \multirow[t]{2}{*}{ Attitudes towards condoms } & Embarrassment & 4917 & -0.19 & -0.24 & -0.14 & $* * *$ \\
\hline & Less fun & 4920 & 0.00 & -0.06 & 0.05 & NS \\
\hline \multirow[t]{2}{*}{ Health beliefs concerning condoms } & Efficacy & 4801 & 0.01 & -0.01 & 0.09 & NS \\
\hline & STI risk & 4810 & -0.00 & -0.07 & 0.06 & NS \\
\hline Anticipated regret & Regret pill only & 4697 & -0.19 & -0.26 & -0.13 & $* * *$ \\
\hline
\end{tabular}

All models control for relevant cognition at age 13/14 years. A positive score indicates a more positive orientation towards condoms with service use, except for the two attitude variables where a negative score is more favourable for condom use. ${ }^{*} p<0.05$, $* * p<0.01, * * * p<0.001$ (two-tailed significance). NS, not significant.

Free condoms was significantly associated with $9 / 14$ condom cognitions at age $15 / 16$ years, after controlling for the relevant condom cognition at age 13/14 years (Table 3 ). On the 'plus' side, free condoms was linked with greater intend discuss and personal responsibility, condom selfefficacy on all three measures and friends' approval, together with reduced embarrassment. However, free condoms was also linked with lower intend condom and pill, and with lower regret pill only.

Looking at the effects of service use in the extended model (Table 4), free condoms was significantly associated with the following positive orientations towards condoms at age 15/16 years, controlling for baseline cognitions and other variables: greater personal responsibility $(p<0.05)$, lower less fun $(p<0.05)$ and greater self-efficacy on all three measures $(p<0.001)$. Coefficients for these variables were reduced compared to those in Table 3 ; this was expected since many of the other factors added to the model (gender, sexual experience, talking with friends and opinions of school sex education effectiveness) are predictors of service use. ${ }^{43}$ In the extended model, free condoms was not associated with any of the condom intentions, with approval of others, with embarrassment, health beliefs or regret pill only.

Although using sexual health services for other purposes, other purpose, was associated with greater condom efficacy and easy use (both $p<0.01$ ), it was also linked to several negative orientations towards condoms at age 15/16 years, controlling for baseline cognitions: reduced intend always, intend condom and pill and regret pill only, and increased less fun (all $p<0.001$ ). As already discussed, some teenagers used services both for free condoms and for other purposes, and the existence of this 'dual purpose' group explains why we found associations between free condoms and both lower intend condom and pill and regret pill only in Table 3. Other purpose was not, unlike free condoms, associated with greater personal responsibility and the two self-efficacy measures easy get and easy negotiate.

Interactions between the two types of service visit were explored, but were found to be not significant. However, the study may not have had the power to detect such an effect, even if it were present.
The effects of free condoms on the three measures of self-efficacy were comparable in magnitude and direction to effects found for sex education ratings, friends' use of condoms or talking with friends about contraception. For other condom cognitions, sex education ratings and peer effects - particularly the latter - were more consistently associated with positively orientated condom cognition change than free condoms or other purpose. Both gender and sexual experience had more complex associations with condom cognition change in the models. Girls were generally more positively orientated towards condoms than boys, with the exception of condom self-efficacy measures, partner approval and condom efficacy. Reporting first sexual intercourse between baseline and follow-up was associated with greater self-efficacy and less embarrassment, but lower intentions to use condoms and reduced regret pill only.

The results for both types of service use contrast with the links found between bought condoms and cognitions, where buying was associated with more positive cognition change for all variables except STI risk and regret pill only, with the coefficient for personal responsibility considerably greater than it was for free condoms.

Did sexual health services do more to promote condoms than simply acting as free suppliers? We used changes in easy get, significantly associated with free condoms and bought condoms in Table 4, as an indicator of a supply effect. This was to help answer the question of whether teenagers reported improved attitudes towards condoms simply because they could obtain condoms more easily, rather than because they had obtained advice from services relating to, for example, condom use and negotiation skills. Adjusting the extended models for changes in easy get resulted in reduced coefficients for condom cognitions found to have significant associations with free condoms, although easy negotiate, easy use and less fun remained significant (Table 5). We could not use changes in easy get to explain changes in cognitions with other purpose, as easy get was not significantly associated with other purpose in Table 4. It thus appears that there were other factors in addition to improved perception of condom supply that lay behind positive changes in condom cognitions: these could include changes in knowledge and confidence. 


\begin{tabular}{|c|c|c|c|c|c|c|c|c|}
\hline & & & & & & & & \\
\hline & $=$ & * * * & 云 & 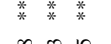 & $\begin{array}{ll}5 \\
z\end{array}$ & $\begin{array}{|cc|}* & \text { 苔 } \\
\end{array}$ & $\begin{array}{l}\bar{z} \\
\bar{z}\end{array}$ & \\
\hline 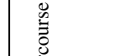 & 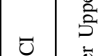 & 19. & . & 030 & $\begin{array}{l}80 \\
0\end{array}$ & 它 & $\therefore$ & $\overrightarrow{0}$ \\
\hline 总 & 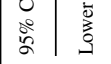 & 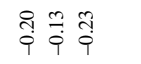 & gे & 홍졍 & 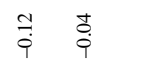 & $\left|\begin{array}{ll}\pi & \pm \\
0 & 0 \\
0 & 0\end{array}\right|$ & $\overline{\bar{\phi}} \overline{\bar{\phi}}$ & สి \\
\hline 密 & & 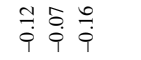 & $\stackrel{\text { to }}{\dot{p}}$ & 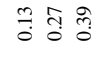 & 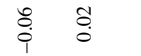 & $\mid \begin{array}{cc}\overline{0} & 0 \\
0 & 0\end{array}$ & 弆 & वे \\
\hline & & 粪: & * & $\tilde{z}_{*} *$ & * & 絭 & $*$ & 菼 \\
\hline & _t & 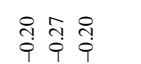 & $\stackrel{t}{\dot{t}}$ & $5=\overline{0}$ & â & $\begin{array}{ll}\overline{0} & 9 \\
0\end{array}$ & $\stackrel{n}{\frac{n}{0}} \frac{0}{0}$ & 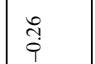 \\
\hline & 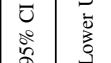 & 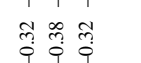 & z & : & $\begin{array}{c}m \\
0 \\
0\end{array}$ & $\begin{array}{ll}8 & 0 \\
0 & 0\end{array}$ & $\frac{1}{8}$ & f \\
\hline 訔 & & 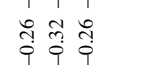 & $\frac{\infty}{\phi}$ & 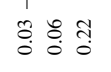 & $\stackrel{\circ}{\circ}$ & $\stackrel{0}{8}$ & 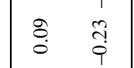 & 足 \\
\hline & $=$ & 员絭学 & $\frac{n}{2}$ & 萎草草 & 公. & 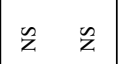 & * & 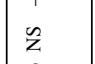 \\
\hline & 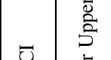 & 8 & 5 & $\stackrel{\infty}{0} \frac{m}{0}$ & $\bar{z}$ & $\mid \begin{array}{ll}\bar{\partial} & \overline{0} \\
0 & \end{array}$ & $\mid \begin{array}{ll}m & \infty \\
0 & 0 \\
0\end{array}$ & $\stackrel{8}{0}$ \\
\hline 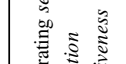 & 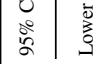 & : & : & $\frac{0}{80}:=$ & 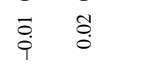 & $\begin{array}{ll}\overline{\bar{i}} & \bar{i} \\
\end{array}$ & $\begin{array}{ll}\bar{a} & \vdots \\
0 & 0\end{array}$ & 8 \\
\hline 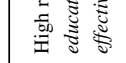 & & $\stackrel{\infty}{\infty} \stackrel{\infty}{0}$ & $\stackrel{\circ}{8}$ & $\stackrel{m}{9} 0$ & $\stackrel{5}{8}$ & 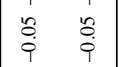 & $\begin{array}{ll}\bar{a} & \overline{0} \\
0\end{array}$ & $\overline{\dot{a}}$ \\
\hline & & 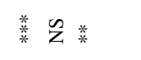 & * & 萻草萻 & $\tilde{z} \quad \tilde{z}$ & $\tilde{z}^{2} \quad *$ & 粰 $\bar{z}$ & \\
\hline 亏 & $=$ & 동영 & $\stackrel{n}{0}$ & 종 $\stackrel{m}{0} 0$ & $\bar{z}$ & $\begin{array}{ll}\bar{\partial} & 0 \\
\dot{0} & 0\end{array}$ & $\stackrel{0}{\stackrel{0}{0}} \stackrel{\infty}{0}$ & $\frac{n}{0}$ \\
\hline & 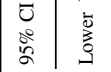 & 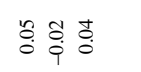 & $\stackrel{0}{\circ}$ & 8 & $\overline{\dot{\phi}}$ & 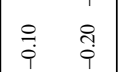 & $\begin{array}{ll}a & a \\
0 & 0\end{array}$ & $\bar{\partial}$ \\
\hline 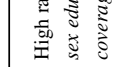 & & $\bar{z}$ & $\stackrel{\circ}{\circ}$ & $\stackrel{\circ}{\circ} \frac{9}{0}$ & $\stackrel{1}{0}$ & 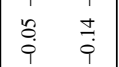 & $\frac{1}{0} \quad \overline{0}$ & $\stackrel{\circ}{8}$ \\
\hline & & 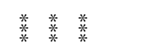 & * & * & * * & * $\quad *$ & * * * & $*$ \\
\hline 彦 & - & 궁 옹영 & $\overrightarrow{3}$ & 뎡 : & 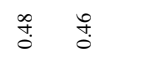 & $\begin{array}{ll}\overline{0} & 0 \\
0\end{array}$ & $\begin{array}{ll}\frac{n}{0} & \frac{\infty}{0} \\
0\end{array}$ & 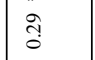 \\
\hline 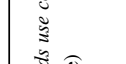 & 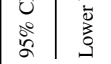 & 뭉 & శె & 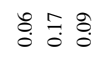 & 号蓉 & 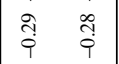 & $\stackrel{8}{8}: 0$ & \pm \\
\hline 部 & & 융 & 형 & 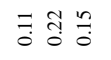 & 웡 娄 & 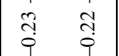 & 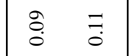 & 8 \\
\hline & & $* * \frac{n}{z}$ & $*$ & s & $* * *$ & $\frac{*}{*}$ & 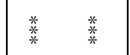 & $\bar{z}$ \\
\hline 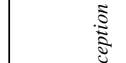 & & 궁 & $\stackrel{\circ}{0}$ & $\stackrel{9}{0}$ & 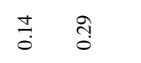 & $\mid \begin{array}{ll}\infty & 0 \\
0 & 0 \\
& 0\end{array}$ & $\stackrel{9}{0}$ & 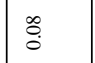 \\
\hline & 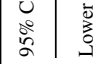 & 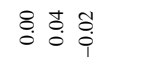 & $\stackrel{5}{0}$ & 08 & $\stackrel{\infty}{0}$ & $\left|\begin{array}{ll}0 & 0 \\
0 & 0 \\
9 & 0\end{array}\right|$ & $\mid \begin{array}{ll}5 & 0 \\
0 & 0 \\
0\end{array}$ & $\stackrel{0}{0}$ \\
\hline 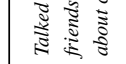 & & 号: & $\bar{z}$ & 고 응 & 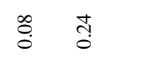 & 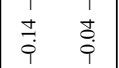 & $\frac{9}{0} \div$ & 8 \\
\hline & & 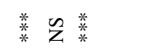 & * & 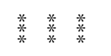 & $* \quad \tilde{z}$ & \begin{tabular}{|l|} 
糡 \\
\end{tabular} & * $\quad \frac{\tilde{z}}{\mathrm{z}}$ & $\tilde{z}$ \\
\hline 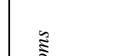 & _. & $\stackrel{9}{0} \stackrel{0}{0}$ & 売 & E. & $\stackrel{\infty}{0}$ & $\left|\begin{array}{ll}0 & 0 \\
\dot{q} & 0 \\
0 & 0\end{array}\right|$ & $\frac{n}{0} \quad \frac{7}{0}$ & $\stackrel{\infty}{0}$ \\
\hline 气ँ & 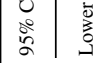 & 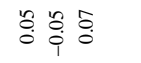 & 5 & 동: & $\begin{array}{ll}0 \\
0\end{array}$ & $\left|\begin{array}{cc}\frac{\infty}{0} & 9 \\
\overline{9} & \end{array}\right|$ & \begin{tabular}{|cc}
0 & $\vdots$ \\
0 & 0
\end{tabular} & $\stackrel{8}{9}$ \\
\hline 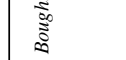 & & 명 : & $\stackrel{9}{0}$ & 중 & $\overline{0} 8$ & $\left|\begin{array}{ll}\overline{\bar{i}} & \multicolumn{1}{c}{} \\
\end{array}\right|$ & 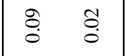 & $\overline{0}$ \\
\hline & & 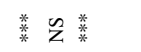 & $\frac{n}{z}$ & 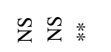 & $\tilde{n} \quad \tilde{z}$ & $\begin{array}{ll}\tilde{z} & \underline{z}\end{array}$ & $* \quad \frac{n}{z}$ & 萃 \\
\hline & 离 & 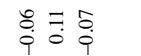 & $\stackrel{8}{8}$ & $\pm \frac{\infty}{0}$ & $\stackrel{\infty}{\circ} \stackrel{0}{0}$ & 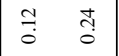 & $\mid \begin{array}{ll}\bar{y} & \stackrel{0}{0} \\
\end{array}$ & $\overline{\bar{p}}$ \\
\hline 气ू & 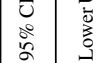 & శึ: & gे & 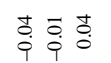 & $\stackrel{\circ}{\overline{0}}$ & $\mid \begin{array}{ll}0 & \infty \\
\stackrel{0}{0} & 0 \\
0\end{array}$ & $\begin{array}{ll} & \frac{n}{0} \\
0 & 0\end{array}$ & $\hat{m}$ \\
\hline 气ั & & $\frac{100}{0}$ & 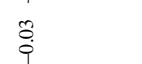 & $\frac{8}{8}:=$ & ప. & $\begin{array}{ll}3 & 0 \\
0 & 0\end{array}$ & $\mid \begin{array}{ll}m & t \\
0 & 0\end{array}$ & z్ \\
\hline & & $\frac{n}{2} \frac{n}{\Sigma} \frac{n}{z}$ & * & 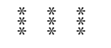 & $\tilde{n} \frac{n}{z}$ & \begin{tabular}{ll|}
$\tilde{z}$ & $*$
\end{tabular} & $\begin{array}{ll}n & n \\
z\end{array}$ & $\tilde{z}$ \\
\hline & $\mid$ & $\overline{3}$ & $\stackrel{9}{0}$ & $\frac{9}{0}$ & $\stackrel{\circ}{\circ}$ & $\mid \begin{array}{ll}\bar{\Xi} & \stackrel{0}{0} \\
0 & \stackrel{q}{i}\end{array}$ & 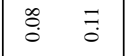 & 索 \\
\hline 彦 & 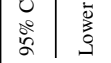 & \%: & $\stackrel{8}{0}$ & 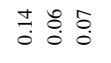 & 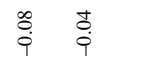 & $\left|\begin{array}{ll}n & n \\
\overline{9} & \stackrel{0}{9}\end{array}\right|$ & 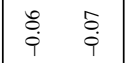 & $\stackrel{ \pm}{9}$ \\
\hline ถั้ & & 売哭 & $\stackrel{\circ}{0}$ & $\frac{9}{9}$ & $\stackrel{8}{8}$ & $\mid$\begin{tabular}{ll|}
0 & 0 \\
0 & 0 \\
0 & 0
\end{tabular} & పे & a \\
\hline & & **: & * & 羏 & $\begin{array}{l}* \\
*\end{array}$ & \begin{tabular}{|c|}
$*$ \\
$*$
\end{tabular} & \begin{tabular}{|ll}
$*$ & $*$ \\
$*$
\end{tabular} & 萃 \\
\hline & 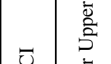 & 정 경 뎡 & $\frac{7}{0}$ & 명 శ్ శ్రి ఫ్రి & శี่ & $\mid \begin{array}{cc}\stackrel{a}{0} & \overline{3} \\
0\end{array}$ & त्व & å \\
\hline 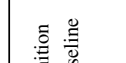 & 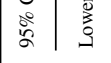 & $\stackrel{\infty}{0}$ 영 경 & $\stackrel{\infty}{0}$ & శె & $\stackrel{6}{\circ}$ & 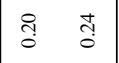 & $\bar{d}$ & $\frac{\infty}{3}$ \\
\hline & 0 & 공 శ్ㅇㅇㅁ & $\stackrel{\circ}{\circ}$ & 정 졍 졍 & $\stackrel{9}{0}$ & 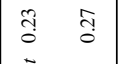 & 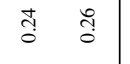 & శี \\
\hline 害离 & & 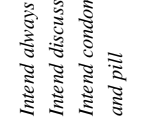 & $\approx$ & 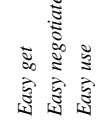 & 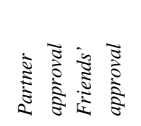 & 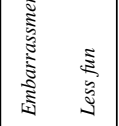 & 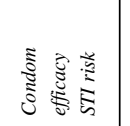 & 赔 \\
\hline & & & 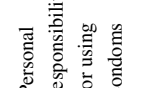 & & 劳 & 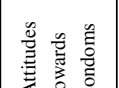 & 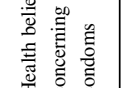 & 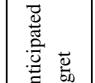 \\
\hline
\end{tabular}


ARTICLE

Table 5 Coefficients for free condoms, adjusting for changes in easy get $(\mathrm{n}=3432)$

\begin{tabular}{|c|c|c|c|c|c|c|c|c|}
\hline & \multicolumn{4}{|c|}{ Original model } & \multicolumn{4}{|c|}{ Controlling for changes in easy get } \\
\hline & \multirow[t]{2}{*}{ Coefficient } & \multicolumn{2}{|l|}{$95 \% \mathrm{CI}$} & \multirow[t]{2}{*}{$p$} & \multirow[t]{2}{*}{ Coefficient } & \multicolumn{2}{|c|}{$95 \% \mathrm{CI}$} & \multirow[t]{2}{*}{$p$} \\
\hline & & Lower & Upper & & & Lower & Upper & \\
\hline Personal responsibility & 0.05 & 0.00 & 0.10 & $*$ & 0.02 & -0.03 & 0.07 & NS \\
\hline Easy negotiate & 0.13 & 0.06 & 0.19 & $* * *$ & 0.07 & 0.01 & 0.13 & * \\
\hline Easy use & 0.13 & 0.07 & 0.19 & $* * *$ & 0.07 & 0.01 & 0.13 & $*$ \\
\hline Less fun & -0.09 & -0.15 & -0.02 & $*$ & -0.08 & -0.15 & -0.01 & $*$ \\
\hline
\end{tabular}

All models control for baseline condom cognition, gender, sexual intercourse, other purpose, bought condoms, talking with friends about contraception, friends use condoms, school sex education ratings. $* p<0.05, * * p<0.01, * * * p<0.001$ (two-tailed significance). NS, not significant.

Lastly, we examined whether the type of service used for condoms (youth or mainstream) was differentially associated with cognitions. The only cognition found to have a significant association with service type, controlling for baseline cognition, was friends' approval: teenagers who visited youth services for condoms reported greater friends' approval than those visiting mainstream services $(n=481$, estimate $0.23,95 \%$ CI $0.07-0.39, p<0.01)$. However this estimate was reduced to 0.02 (95\% CI -0.16 to $0.21, \mathrm{NS}$ ) when other factors (gender, sexual intercourse, etc.) were added as for the extended models above.

\section{Discussion}

In Part 1 the independent direct effect of obtaining free condoms from services on greater condom consistency, after controlling for condom and pill cognitions, provides evidence for a positive supply effect of services on condom use comparable in magnitude to the descriptive norm relating to friends' use of condoms. There were indications that service visits were also associated with changes in attitudes towards condoms, although causation in this crosssectional model is unclear. Ideally the models of condom consistency should have been prospective, and there were also limitations on the extent to which we have been able to characterise the nature of teenagers' sexual relationships.

In the longitudinal models in Part 2 there is also some uncertainty as to whether the links between service use and cognition change over the period from baseline to followup reflect causation from services to cognitions, rather than changes in the reverse direction or changes in a third variable such as general confidence. It appeared that using services to obtain condoms was not as pervasive (in the sense of being linked with as many condom cognitions) nor generally as strongly associated with positive orientation towards condoms as peer or school sex education influences, insofar as we were able to measure these influences here. We lacked information on other possible sources of influence on condom use, such as the family and media. Obtaining free condoms from services was not associated with changes in condom intentions, unlike most of the other factors we measured. These findings are not surprising when we compare the short duration of a service visit with the more enduring influences of, for example, friendships. Nevertheless, it appeared that using services for free condoms may have been relatively successful in promoting greater condom self-efficacy, as well as being associated with a greater sense of personal responsibility and more positive attitudes towards condoms.

We found that several cognitions that were associated with service use in the longitudinal models for all teenagers were also cognitions that were associated with condom consistency in the cross-sectional model of teenagers with more than one sexual experience. However, we do not have enough evidence to show that the association between using services and using condoms consistently is in part a causal relationship mediated by a change in cognitions. In order to model cognition change in teenagers with more than one sexual experience, it would seem desirable to include more descriptors of the level of sexual experience and type of relationship, and this is outside the scope of this paper.

The evidence that sexual health services do more to promote condoms than act as free suppliers is necessarily indirect and tentative. We do not know what contact teenagers had with service staff, and indeed contact may have been minimal when accessing free condoms in order to avoid identification or embarrassment. Teenagers may be more favourably disposed to use condoms if they can get them free, regardless of any counselling efforts of service staff. It would be unwise to ascribe cognition changes simply to counselling effects of services, since buying condoms was associated with a wider range of more strongly positive changes in cognitions than either type of service visit. Clearly, this issue would best be addressed with a controlled study that compared the effectiveness of different clinic-based counselling interventions on teenagers' use of condoms.

However, it appeared that teenagers using services for purposes other than acquiring condoms were less likely to use condoms consistently and had conflicting motivations regarding condom use. (As already noted, some teenagers used services both for free condoms and for other purposes especially the pill, but we do not know which was the main purpose of service visits.) In the cross-sectional model of condom consistency, the finding that teenagers are less consistent condom users if they have had more than one sexual partner suggests that teenagers may become less committed to condoms with greater sexual experience and/or more casual sexual relationships. Increased pill use may partly account for this, and ease of suggesting the pill to one's sexual partner was inversely associated with condom consistency. Noting that sexual experience was also linked in the longitudinal models with reduced intentions to use condoms and reduced anticipated regret at using the pill only, it appears that service staff may have to devote more effort towards persuading sexually experienced teenagers on the pill that they should use dual protection. A further shortcoming of services appears to be their lack of impact in countering negative attitudes of condoms in relation to embarrassment, which had an inverse association with consistent condom use. The largest reductions in embarrassment were linked with sexual experience and friends' use of condoms: it is clearly more difficult for services to influence individual attitudes here, but potentially more worthwhile than a narrow focus on health beliefs concerning condoms, which were not good predictors of condom consistency either in our models or in the model developed by Abraham et al. ${ }^{46}$

In developing effective messages to encourage more consistent use of condoms and dual protection, ${ }^{51}$ services might take note of the findings that descriptive norms (friends' perceived use of condoms) were a strong predictor of both consistent condom use and of positive cognition change from age 13/14 to age 15/16 years. Youth services may have the most potential to influence this peer group 


\section{ARTICLE}

effect through a more extensive engagement with youth culture. Although our sample size was relatively small, there were indications of greater condom consistency and increased friends' approval amongst those using this type of service. More generally, encouraging friends and partners to use services together may change teenagers' perceptions of peer condom use, reduce embarrassment and make their own use of condoms more likely.

\section{Acknowledgement}

The authors are grateful to Geoff Der for providing statistical advice.

Statements on funding and competing interests

Funding. This study was funded by the UK Medical Research Council. The Health Education Board for Scotland funded the development of the SHARE programme.

Competing interests. None identified.

References

1 Wellings K, Nanchahal K, Macdowall W, McManus S, Erens B Mercer $\mathrm{CH}$, et al. Sexual behaviour in Britain: early heterosexual experience. Lancet 2001; 358: 1843-1850.

2 Wight D, Henderson M. The diversity of young people's heterosexual behaviour. In: Burtney E, Duffy M (eds), Young People and Sexual Health: Individual, Political and Individual Contexts. London, UK: Palgrave Macmillan, 2004; 15-33.

3 DiClemente RJ, Durbin M, Siegel D, Krasnovsky F, Lazarus N, Comacho T. Determinants of condom use among junior high school students in a minority, inner-city school district. Pediatrics 1992; 89: 197-202.

4 Abraham CS, Sheeran P, Abrams D, Spears R. Health beliefs and teenage condom use: a prospective study. Psychol Health 1996; 11: 641-655.

5 Anderson JE, Santelli J, Gilbert BC. Adolescent dual use of condoms and hormonal contraception: trends and correlates 1991-2001. Sex Transm Dis 2003; 30: 719-722.

6 Abraham C, Sheeran P, Spears R, Abrams D. Health beliefs and promotion of HIV-preventive intentions among teenagers: a Scottish perspective. Health Psychol 1992; 11: 363-370.

7 Baele J, Dusseldorp E, Maes S. Condom use self-efficacy: effect on intended and actual condom use in adolescents. J Adolesc Health 2001; 28: $421-431$.

8 Basen-Engquist K, Parcel GS. Attitudes, norms, and self-efficacy: a model of adolescents' HIV-related sexual risk behavior. Health Educ $Q$ 1992; 19: 263-277.

9 DiIorio C, Dudley WN, Kelly M, Soet JE, Mbwara J, Potter JS. Social cognitive correlates of sexual experience and condom use among 13through 15-year-old adolescents. J Adolesc Health 2001; 29: 208-216.

10 Lindsay J, Smith AMA, Rosenthal DA. Conflicting advice? Australian adolescents' use of condoms or the pill. Fam Plann Perspect 1999; 31: 190-194.

11 Helweg-Larsen M, Collins BE. The UCLA Multidimensional Condom Attitudes Scale: documenting the complex determinants of condom use in college students. Health Psychol 1994; 13: 224-237.

12 Murphy JJ, Boggess S. Increased condom use among teenage males, 1988-1995: the role of attitudes. Fam Plann Perspect 1998; 30 : 276-280.

13 Pleck JH, Sonenstein FL, Ku L. Changes in adolescent males use of and attitudes toward condoms, 1988-1991. Fam Plann Perspect 1993; 25: 106-110.

14 Ellen JM, Adler N, Gurvey JE, Millstein SG, Tschann J. Adolescent condom use and perceptions of risk for sexually transmitted diseases: a prospective study. Sex Transm Dis 2002; 29: 756-762.

15 Rosengard C, Adler NE, Gurvey JE, Dunlop MBV, Tschann JM, Millstein SG, et al. Protective role of health values in adolescents' future intentions to use condoms. J Adolesc Health 2001; 29: 200-207.

16 Schaalma H, Kok G, Peters L. Determinants of consistent condom use by adolescents: the impact of experience of sexual intercourse. Health Educ Res 1993; 8: 255-269.

17 Henderson M, Wight D, Raab G, Abraham C, Buston K, Hart G, et al. Heterosexual risk behaviour among young teenagers in Scotland. $J$ Adolesc 2002; 25: 483-494.

18 Gebhardt WA, Kuyper L, Greunsven G. Need for intimacy in relationships and motives for sex as determinants of adolescent condom use. J Adolesc Health 2003; 33: 154-164.

19 Holland J, Ramasanoglu C, Sharpe S. The Male in the Head: Young People, Heterosexuality and Power. London, UK: Tufnell Press, 1998.

20 Ford K, Sohn W, Lepkowski J. Characteristics of adolescents' sexual partners and their association with use of condoms and other contraceptive methods. Fam Plann Perspect 2001; 33: 100-105.

21 Manlove J, Ryan S, Franzetta K. Patterns of contraceptive use within teenagers' first sexual relationships. Perspect Sex Reprod Health 2003 ; 35: $246-255$.

22 Clements S, Stone N, Diamond I, Ingham R. Modelling the spatial distribution of teenage conception rates within Wessex. Br J Fam Plann 1998; 24: 61-71.

23 Diamond I, Clements S, Stone N, Ingham R. Spatial variation in teenage conceptions in south and west England. J R Stat Soc Ser A Stat Soc 1999; 162: 273-289.

24 Wilson S, Daniel S, Pearson J, Hopton C, Madeley R. An evaluation of a new teenage clinic and its impact on teenage conceptions in Nottingham from 1986 to 1992 . Contraception 1994; 50: 77-86.

25 Paton D. The economics of family planning and underage conceptions. J Health Econ 2002; 21: 207-225.

26 Kamb ML, Fishbein M, Douglas JM, Rhodes F, Rogers J, Bolan G, et al. Efficacy of risk-reduction counseling to prevent human immunodeficiency virus and sexually transmitted diseases: a randomized controlled trial. JAMA 1998; 280: 1161-1167.

27 National Institute of Mental Health Multisite HIV Prevention Trial Group. Social-cognitive theory mediators of behavior change in the National Institute of Mental Health Multisite HIV Prevention Trial. Health Psychol 2001; 20: 369-376.

28 Albarracin D, McNatt PS, Klein CTF, Ho RM, Mitchell AL, Kumkale GT. Persuasive communications to change actions: an analysis of behavioral and cognitive impact in HIV prevention. Health Psychol 2003: 22: 166-177.

29 de Visser RO, Smith AM. When always isn't enough: implications of the late application of condoms for the validity and reliability of selfreported condom use. AIDS Care 2000; 12: 221-224.

30 Crosby RA, DiClemente RJ, Wingood GM, Lang D, Harrington KF. Value of consistent condom use: a study of sexually transmitted disease prevention among African American adolescent females. Am J Public prevention among African An

31 Lindemann DF, Brigham TA. A Guttman scale for assessing condom use skills among college students. AIDS Behav 2003; 7: 23-27.

32 Crosby R, DiClemente RJ, Wingood CM, Sionean C, Cobb BK, Harrington $\mathrm{K}$, et al. Correct condom application among AfricanAmerican adolescent females: the relationship to perceived self-efficacy and the association to confirmed STDs. J Adolesc Health self-efficacy and the

33 Schuster MA, Bell RM, Berry SH, Kanouse DE. Impact of a high school condom availability program on sexual attitudes and behaviors. Fam Plann Perspect 1998; 30: 67-72, 88

34 Guttmacher S, Lieberman L, Ward D, Freudenberg N, Radosh A, DesJarlais D. Condom availability in New York City public high schools: relationships to condom use and sexual behavior. Am J Public Health 1997; 87: 1427-1433.

35 Furstenberg FF, Geitz LM, Teitler JO, Weiss CC. Does condom availability make a difference? An evaluation of Philadelphia's Health Resource Centers. Fam Plann Perspect 1997; 29: 123-127.

36 Kirby D, Brener ND, Brown NL, Peterfreund N, Hillard P, Harrist R. The impact of condom availability [correction of distribution] in Seattle schools on sexual behavior and condom use. Am J Public Health 1999; 89: 182-187, erratum in Am J Public Health 1999; 89: 422.

37 Wolk LI, Rosenbaum R. The benefits of school-based condom availability: cross-sectional analysis of a comprehensive high schoolbased program. J Adolesc Health 1995; 17: 184-188.

38 Fortenberry JD. Clinic-based service programs for increasing responsible sexual behavior. J Sex Res 2002; 39: 63-66.

39 Jaccard J. Adolescent contraceptive behavior: the impact of the provider and the structure of clinic-based programs. Obstet Gynecol 1996; 88(Suppl. 3): 57S-64S

40 DiCenso A, Guyatt G, Willan A, Griffith L. Interventions to reduce unintended pregnancies among adolescents: systematic review of randomised controlled trials. BMJ 2002; 324: 1426-1434.

41 Robin L, Dittus P, Whitaker D, Crosby R, Ethier K, Mezoff J, et al. Behavioral interventions to reduce incidence of HIV, STD, and pregnancy among adolescents: a decade in review. $J$ Adolesc Health 2004; 34: 3-26.

42 Wight D, Raab G, Henderson M, Abraham C, Buston K, Hart G, et al. The limits of teacher-delivered sex education: interim behavioural outcomes from randomised trial. BMJ 2002; 324: 1430-1433.

43 Parkes A, Wight D, Henderson M. Teenagers' use of sexual health services: perceived need, knowledge and ability to access. J Fam Plann Reprod Health Care 2004; 30: 217-224.

44 Health Protection Agency. Reviewing the Focus. HIV and Other Sexually Transmitted Infections in the UK. An Update: November 2003. London, UK: Health Protection Agency; 2003.

45 Johnson AM, Mercer CH, Erens B, Copas AJ, McManus S, Wellings K, et al. Sexual behaviour in Britain: partnerships, practices, and HIV risk behaviours. Lancet 2001; 358: 1835-1842.

46 Abraham C, Henderson M, Der G. Cognitive impact of a researchbased school sex education programme. Psychol Health 2004; 19: 689-703.

47 Ajzen I. Models of human social behavior and their application to health psychology. Psychol Health 1998; 13: 735-739.

48 Ajzen I. Nature and operation of attitudes. Ann Rev Psychol 2001; 52: $27-58$.

49 Armitage CJ, Conner M. Efficacy of the theory of planned behaviour: a meta-analytic review. Br J Soc Psychol 2001; 40: 471-499.

50 Godin G, Kok G. The theory of planned behavior: a review of its applications to health-related behaviors. Am J Health Promot 1996; 11: 87-98.

51 Abraham C, Krahe B, Dominic R, Fritsche I. Do health promotion messages target cognitive and behavioural correlates of condom use? A content analysis of safer sex promotion leaflets in two countries. $\mathrm{Br} \mathrm{J}$ Health Psychol 2002; 7: 227-246. 